DISTRIBUTION STATEMENT A. Approved for public release; distribution is unlimited.

\title{
PCoD Lite - Using an Interim PCoD Protocol to Assess the Effects of Disturbance Associated with US Navy Exercises on Marine Mammal Populations
}

\author{
Cormac Booth \\ SMRU Marine Ltd. \\ New Technology Centre, North Haugh \\ St Andrews, UK \\ phone: +44-131-46-38-555 email:cgb@smrumarine.com \\ Mark Burgman \\ Australian Centre of Excellence for Risk Analysis (ACERA) \\ School of Botany \\ The University of Melbourne \\ Australia \\ phone:+61383444405 email:markab@unimelb.edu.au \\ Carl Donovan \\ DMP Statistical Solutions UK Ltd. \\ The Coach House Office, Mount Melville House \\ Mount Melville \\ St. Andrews, UK \\ phone: +44-1334 477544 email: carl@dmpstats.com \\ John Harwood, Len Thomas, \& Robert Schick \\ Centre for Research into Ecological and Environmental Modelling (CREEM) \\ University of St Andrews \\ St Andrews, UK \\ phone: +44-7872415064 fax:+44-1334461800 email: jh7@st-andrews.ac.uk \\ phone: +44-1334 461801 fax: +44-1334 461800 email: len@mcs.st-and.ac.uk \\ phone: +44-1334 461829 fax:+44-1334461800 email: rss5@st-andrews.ac.uk \\ Jason Wood \\ SMRU LLC \\ 108 Skookum Tom Road \\ Friday Harbor, WA, USA \\ phone: 1-360-370-5493 email: jw@smrullc.com \\ Award Number: N000141410406 \\ http://www.smrumarine.com/pcod
}




\section{Report Documentation Page}

Form Approved

OMB No. 0704-0188

Public reporting burden for the collection of information is estimated to average 1 hour per response, including the time for reviewing instructions, searching existing data sources, gathering and maintaining the data needed, and completing and reviewing the collection of information. Send comments regarding this burden estimate or any other aspect of this collection of information,

including suggestions for reducing this burden, to Washington Headquarters Services, Directorate for Information Operations and Reports, 1215 Jefferson Davis Highway, Suite 1204, Arlington

VA 22202-4302. Respondents should be aware that notwithstanding any other provision of law, no person shall be subject to a penalty for failing to comply with a collection of information if it

does not display a currently valid OMB control number.

1. REPORT DATE

30 SEP 2014

2. REPORT TYPE

3. DATES COVERED

00-00-2014 to 00-00-2014

4. TITLE AND SUBTITLE

PCoD Lite - Using an Interim PCoD Protocol to Assess the Effects of Disturbance Associated with US Navy Exercises on Marine Mammal Populations

5a. CONTRACT NUMBER

5b. GRANT NUMBER

5c. PROGRAM ELEMENT NUMBER

6. AUTHOR(S)

5d. PROJECT NUMBER

5e. TASK NUMBER

5f. WORK UNIT NUMBER

7. PERFORMING ORGANIZATION NAME(S) AND ADDRESS(ES)

8. PERFORMING ORGANIZATION

SMRU Marine Ltd,New Technology Centre, North Haugh,St Andrews, $\mathbf{U K}$,

9. SPONSORING/MONITORING AGENCY NAME(S) AND ADDRESS(ES)

10. SPONSOR/MONITOR'S ACRONYM(S)

11. SPONSOR/MONITOR'S REPORT $\operatorname{NUMBER}(\mathrm{S})$

12. DISTRIBUTION/AVAILABILITY STATEMENT

Approved for public release; distribution unlimited

13. SUPPLEMENTARY NOTES

14. ABSTRACT

15. SUBJECT TERMS

16. SECURITY CLASSIFICATION OF:

a. REPORT

b. ABSTRACT

c. THIS PAGE

unclassified

unclassified

unclassified

17. LIMITATION OF ABSTRACT

Same as

Report (SAR)
18. NUMBER OF PAGES

5 19a. NAME OF

RESPONSIBLE PERSON 


\section{LONG-TERM GOALS}

The approach that will be developed in this project has the potential for operational use by the US Navy as part of its environmental impact assessments. In future, these assessments will likely be required to provide information on the potential population-level consequences of exposure to anthropogenic noise from Navy activities as well as the number of animals that are exposed.

In order to issue an incidental harassment authorization to the US Navy under the Marine Mammal Protection Act, the Office of Protected Resources must ensure that "the specified activity ...cannot be reasonably expected to, and is not reasonably likely to, adversely affect the species or stock through effects on annual rates of recruitment or survival". We have recently developed an interim protocol (Harwood et al. 2014) that can be used to implement the framework for assessing the population consequences of acoustic disturbance for marine mammals originally developed by a panel appointed by the US National Research Council (NRC 2005). However, the interim protocol was designed to assess the potential impact of disturbance associated with the construction and operation of offshore renewable energy developments on marine mammal populations in UK waters.

\section{OBJECTIVES}

The main objective of the proposal is to illustrate how the interim PCoD protocol can be used to inform the process of determining whether or not Navy activities are likely to have a negligible impact on populations of one priority species at two different Navy ranges. For this project, we are adapting the protocol so that it can be used to forecast the potential effects of disturbance associated with Navy exercises on populations of beaked whales (particularly Blainville's beaked whale Mesoplodon densirostris) at the Atlantic Undersea Test and Evaluation Center (AUTEC), Bahamas, and at the Pacific Missile Range Facility (PMRF), Hawaii.

\section{APPROACH}

We have formed a Steering Committee for the project in order to make a final decision on the species to be investigated and the study sites. This steering committee comprises members of the US Navy, NOAA, the Marine Mammal Commission and ensures a broad review and steer on the project and its objectives. The Steering Committee will also agree on the composition of a wider stakeholder group consisting of representatives of other organizations that are likely to be interested in the project, and who will be provided with copies of project reports.

We collated a list of experts on beaked whales with the Steering Committee inputting. We invited each of those experts to participate in an solicited expert judgement exercise. This involves each expert being supplied with an electronic questionnaire allowing them to provide the information required to parameterize the relationships shown in Fig. 1 relatively easily. A similar questionnaire was used successfully during the development of the interim PCoD protocol (see Appendix 1 of Harwood et al. 2014). This questionnaire uses the 4-step approach developed by Spiers-Bridge et al. (2010) to provide robust responses from an expert elicitation process. We will analyze the results of this first round of consultation using the techniques described in the preceding section. 


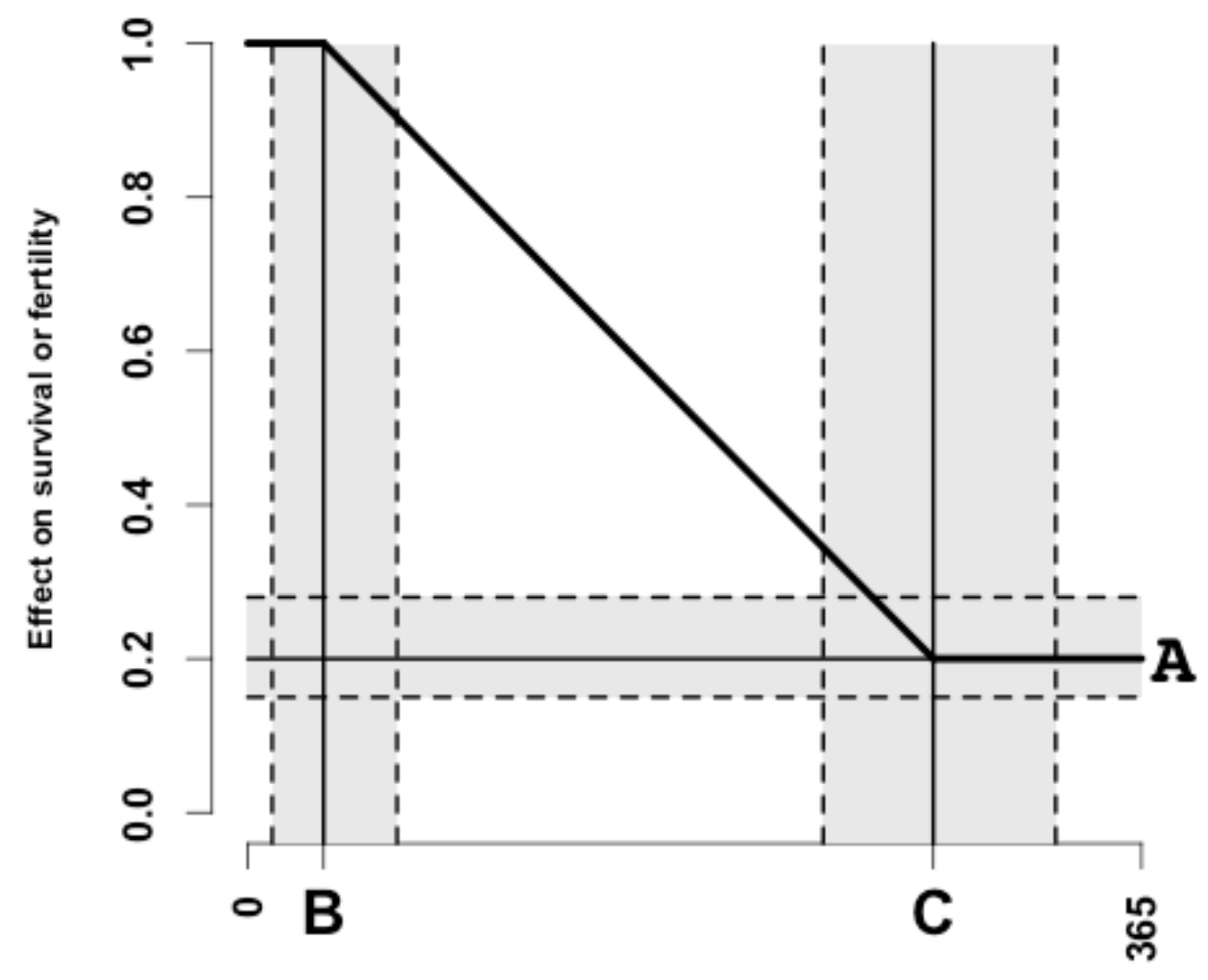

Days of disturbance

Figure 1. Hypothetical relationship between the number of days of disturbance experienced by an individual and its effect on the probability of survival or of giving birth (fertility). $A$ is the maximum effect of disturbance (in this case, the actual probability of survival will be the population survival rate multiplied by 0.2 ), $B$ is the number of days of disturbance an individual can tolerate before its survival or fertility is affected, and $C$ is the number of days of disturbance required to cause the maximum effect. The shaded areas indicate the experts' estimates of the likely range around the best estimates of $A, B$ and $C$.

This consultation will be followed by a workshop of invited experts who will use the Delphi process (Delbecq et al. 1975, MacMillan \& Marshall 2006), in which experts are asked to reconsider their opinions in the light of what other experts have said. This has been shown to substantially improve the reliability of the elicitation results (Burgman et al. 2011). It is intended that this process will refine responses, improve their reliability and, if possible, reduce the levels of associated uncertainty. This workshop will agree on the final forms of the functions relating disturbance to changes in survival/fertility for the target species, and the levels of uncertainty to be associated with them.

We will then modify the computer code written to implement the interim PCoD protocol to account for different nature of disturbance events (the interim code was developed to explore the impact of long bouts of pile-driving) and to provide the metrics for assessing negligible impact agreed by the Steering Committee. An interim report describing the results of the expert elicitation and illustrating the kinds of forecasts that can be provided for the study populations will be compiled and circulated to the Steering Group; the report will subsequently be discussed at a face-to-face meeting. A revised report 
based on feedback from this meeting will be circulated to members of the stakeholder group for their comments. A final report that takes account of comments made by the stakeholder group, and which includes an assessment of the work that would be required to replicate this assessment for other species at different Navy ranges, will then be agreed with the Steering Group at a final meeting. Once accepted by the Steering Group, this report will be published on line.

\section{WORK COMPLETED}

The project is underway and we are currently four months into the project schedule. So far we have assembled a Steering Committee comprising Navy, NOAA and MMC personnel to guide and inform the project direction.

We have recently completed the first phase of the solicited expert judgement. We are now analyzing these results and preparing for the Delphi process workshop.

\section{RESULTS}

We do not have results yet, but as noted above, we have completed the data collection element of the soliciting expert judgement section. We approached 104 marine mammal experts

\section{IMPACT/APPLICATIONS}

The approach that will be developed in this project has the potential for operational use by the Navy as part of its environmental impact assessments. In future, these assessments will likely be required to provide information on the potential population-level consequences of exposure to anthropogenic noise from Navy activities as well as the number of animals that are exposed. As noted above, the Office of Protected Resources is required to determine that an activity will cause negligible impact to the animal species or stocks inhabiting the area as part of the permitting process; this involves examining the potential effect of the impact on demographic parameters. The interim PCoD approach is designed to provide exactly this information in situations where detailed scientific knowledge required for the full PCAD approach is lacking. To ensure maximum relevance, we include both representatives of the Navy offices charged with producing environmental impact assessments and representatives of the regulatory office on the project steering committee.

\section{REFERENCES}

Delbecq, A., Van de Ven, A., \& Gustafson, D. (1975). Group techniques for program planning: a guide to nominal group and Delphi processes. Glenview, IL: Scott, Foresman and Company.

Harwood, J., S. King, R. Schick, C. Donovan and C. Booth 2014. A Protocol for Implementing the Interim Population Consequences of Disturbance (PCoD) Approach: Quantifying and Assessing the Effects of UK Offshore Renewable Energy Developments on Marine Mammal Populations. Scottish Marine and Freshwater Science 5(2). http://www.scotland.gov.uk/Resource/0044/00443360.

MacMillan, D. C., \& Marshall, K. (2006). The Delphi process - an expert-based approach to ecological modelling in data-poor environments. Animal Conservation, 9(1), 11-19. 
National Research Council. (2005). Marine Mammal Populations and Ocean Noise : Determining when noise causes biologically significant effects. The National Academy Press. Washington D.C.

Speirs-Bridge, A., Fidler, F., McBride, M., Flander, L., Cumming, G., \& Burgman, M. (2010).

Reducing overconfidence in the interval judgments of experts. Risk Analysis, 30(3), 512-523. 